\title{
Exploring spatio-temporal changes in the demersal and benthopelagic assemblages of the north- western Ionian Sea (central Mediterranean Sea)
}

\author{
R. Carlucci ${ }^{1,2}$, V. Bandelj ${ }^{3}$, P. Ricci ${ }^{1,2, *}$, F. Capezzuto ${ }^{1,2}$, L. Sion ${ }^{1,2}$, P. Maiorano ${ }^{1,2}$, \\ A. Tursi ${ }^{1,2}$, C. Solidoro ${ }^{3}$, S. Libralato ${ }^{3}$ \\ ${ }^{1}$ Department of Biology, University of Bari, Via Orabona, 4 - 70125 Bari, Italy \\ ${ }^{2}$ CoNISMa, Piazzale Flaminio, 9 Roma, Italy \\ ${ }^{3}$ OGS (Istituto Nazionale di Oceanografia e di Geofisica Sperimentale), Oceanography Division, \\ Via Beirut 2/4 (Ex-Sissa building), 34151 Trieste, Italy
}

\begin{abstract}
An exploration of the structure of demersal and benthopelagic assemblages in the north-western Ionian Sea was carried out by means of a set of statistical analyses. Self-organising map (SOM) and clustering methods applied to 183 taxa and their biomass $\left(\mathrm{kg} \mathrm{km}^{-2}\right)$ provided the classification of 1288 experimental hauls exploring the bathymetric range 10-800 $\mathrm{m}$ from 1995 to 2012. Six clusters were identified according to their similarities in species abundances (biomass), confirming the depth gradient as the main structuring agent. In order to identify key representative species in each cluster, the taxa were ranked by means of an indicator value index (IndVal) and the contribution of species to beta diversity (BD). Furthermore, the clusters were described by means of environmental and fishing characteristics. Particular habitat type, distance to canyon and fishing effort segregated the assemblages on the coastal shelf and slope. Temporal differences were detected in 2 bathyal groups, which were most likely affected by the 1990s environmental change in the deepwater circulation known as the Eastern Mediterranean Transient. The overall total $\mathrm{BD}$ in the study area was calculated as 0.79 , with a temporal decrease observed at a rate of $0.7 \% \mathrm{yr}^{-1}$. The approaches used are useful to identify and characterize the species aggregations inside complex faunal assemblages, without a priori assumptions about data distribution. These results can be a starting point for defining functional groups for Mediterranean food web modelling approaches, as well as for identifying indicator species to assess the environmental status in the context of the Marine Strategy Framework Directive.
\end{abstract}

KEY WORDS: Self-organising map - SOM - Demersal and benthopelagic assemblage . Beta-diversity $\cdot$ Indicator species $\cdot$ North-western Ionian Sea

\section{INTRODUCTION}

The Mediterranean Sea is a marine biodiversity hotspot subjected to various anthropogenic pressures including intense exploitation, fish farming, nutrient discharge, pollution, shipping and climate change (Ramirez-Llodra et al. 2011, Coll et al. 2012, Lazzari et al. 2014). The cumulative impacts of these might drive changes in the distribution and abundance of

\footnotetext{
${ }^{*}$ Corresponding author: pasquale.ricci@uniba.it
}

marine assemblages as well as in the structure and functioning of food webs (Bianchi et al. 2012, Coll \& Libralato 2012, Quetglas et al. 2013). Faunal assemblages represent a level of aggregation of marine species whose distribution in space and time overlaps in a certain area, sharing the same habitat, bathymetric range and several environmental gradients (García-Rodriguez et al. 2011). Several studies have been carried out with the aim of describing the

() The authors 2018. Open Access under Creative Commons by Attribution Licence. Use, distribution and reproduction are unrestricted. Authors and original publication must be credited. 
pattern of distribution, abundance and diversity of faunal assemblages in the Mediterranean Sea and their changes over time (García-Rodriguez et al. 2011, Gaertner et al. 2013, Granger et al. 2015) as well as their interactions with fishing activities (D'Onghia et al. 2003, Massutí \& Renones 2005).

The north-western (NW) Ionian Sea represents an ideal case for a descriptive analysis of spatiotemporal changes of marine communities through the use of a set of statistical methods. In fact, this basin extends for a wide area of the Central Mediterranean Sea, contains a variety of habitats, and includes a wide spectrum of oceanographic, topographic and geomorphological conditions, typical of the Mediterranean Sea, which are reflected in the distribution and abundance of the demersal resources as well as in the biodiversity detected (Maiorano et al. 2010). Previous analyses characterized the demersal assemblage in the NW Ionian Sea at different spatial scales, identifying depth as the main environmental factor structuring the demersal and benthopelagic assemblages (D'Onghia et al. 2003, Capezzuto et al. 2010). Although analyses of environmental variables in a few cases and on a single commercial species have been carried out (D'Onghia et al. 2012a), information on other variables and a multi-species approach has not previously been used.

The objective of the present study was to identify the main demersal and benthopelagic assemblages in the community sampled by the MEDITS trawl survey in the NW Ionian Sea, to identify key species indicators of the assemblages from the point of view of abundance, specificity, fidelity and contribution to beta diversity, and finally to describe the abiotic habitat of such assemblages using variables related to environmental and fishing pressures. In particular, the structure of assemblages was explored through the use of a self-organising map (SOM), an unsupervised iterative clustering technique based on neural networks which is applied to disaggregated biomass data to define clusters of sampling sites (hauls) with a common composition.

The SOM was further clustered using the Ward clustering method, and a combined indicator of species abundance and frequency of occurrence (indicator value index, IndVal; Dufrêne \& Legendre 1997) was assigned to each cluster in order to identify indicator species of each obtained assemblage. Finally, the variability of species composition through hauls was used to determine regional diversity, i.e. beta diversity (sensu Legendre \& De Cáceres 2013). Regional diversity was then partitioned by species, sites, time and assemblages, allowing the identifica- tion of the main contributions relevant to characterize the biological community of the area. The analysis represents a basis for defining the aggregation criteria of species typical to the Mediterranean Sea to be considered, for example, for the definition of basic spatial aggregation units and functional groups in complex ecosystem models (Plaganyi 2007, Grüss et al. 2018).

\section{MATERIALS AND METHODS}

\section{Study area}

The NW Ionian Sea (central Mediterranean Sea), corresponding to FAO Geographical Sub Area (GSA) 19 of the Mediterranean Sea, extends from Cape Otranto to Cape Passero along a coastline of about $1000 \mathrm{~km}$ and across an area of approximately $16500 \mathrm{~km}^{2}$ in a depth range between 10 and $800 \mathrm{~m}$ (Fig. 1). The NW Ionian Sea is divided by the Taranto Valley into an eastern sector represented by a broad continental shelf and a south-western sector where the shelf is generally very limited and many submarine canyons are located along the coasts (Rossi \& Gabbianelli 1978). The area includes a complex set of habitats hosting important demersal fishery resources (Maiorano et al. 2010, Carlucci et al. 2016, Russo et al. 2017) and several hot spots of biodiversity such as cold water coral habitats and submarine canyons (Capezzuto et al. 2010, D'Onghia et al. 2011, 2012b, 2016, Vassallo et al. 2017). From a hydrographic point of view, the Ionian Sea is characterized by a complex system of water circulation in surface and deep layers (Civitarese et al. 2010 and references therein), showing a general cyclonic circulation markedly influenced by the cold, dense deep-water masses of the Adriatic Sea flowing in through the Otranto Channel. Hydrographic observations and current measurements performed in the 1990s revealed strong modifications in the dynamics of the entire water column termed the Eastern Mediterranean Transient (EMT) (Klein et al. 1999).

In the NW Ionian Sea, fishing activities occur in water depths from coastal waters to about $800 \mathrm{~m}$. Gallipoli, Taranto, Crotone and Reggio Calabria host the most important fishing fleets. In GSA 19, trawlers represent about $21 \%$ in number, $64 \%$ in gross tonnage and $56 \%$ in engine power of the total fleet (Carlucci et al. 2016, Russo et al. 2017). Although the other fisheries might impact the demersal communities of the Ionian Sea indirectly, here we focussed on the trawl fisheries which represent the main direct 


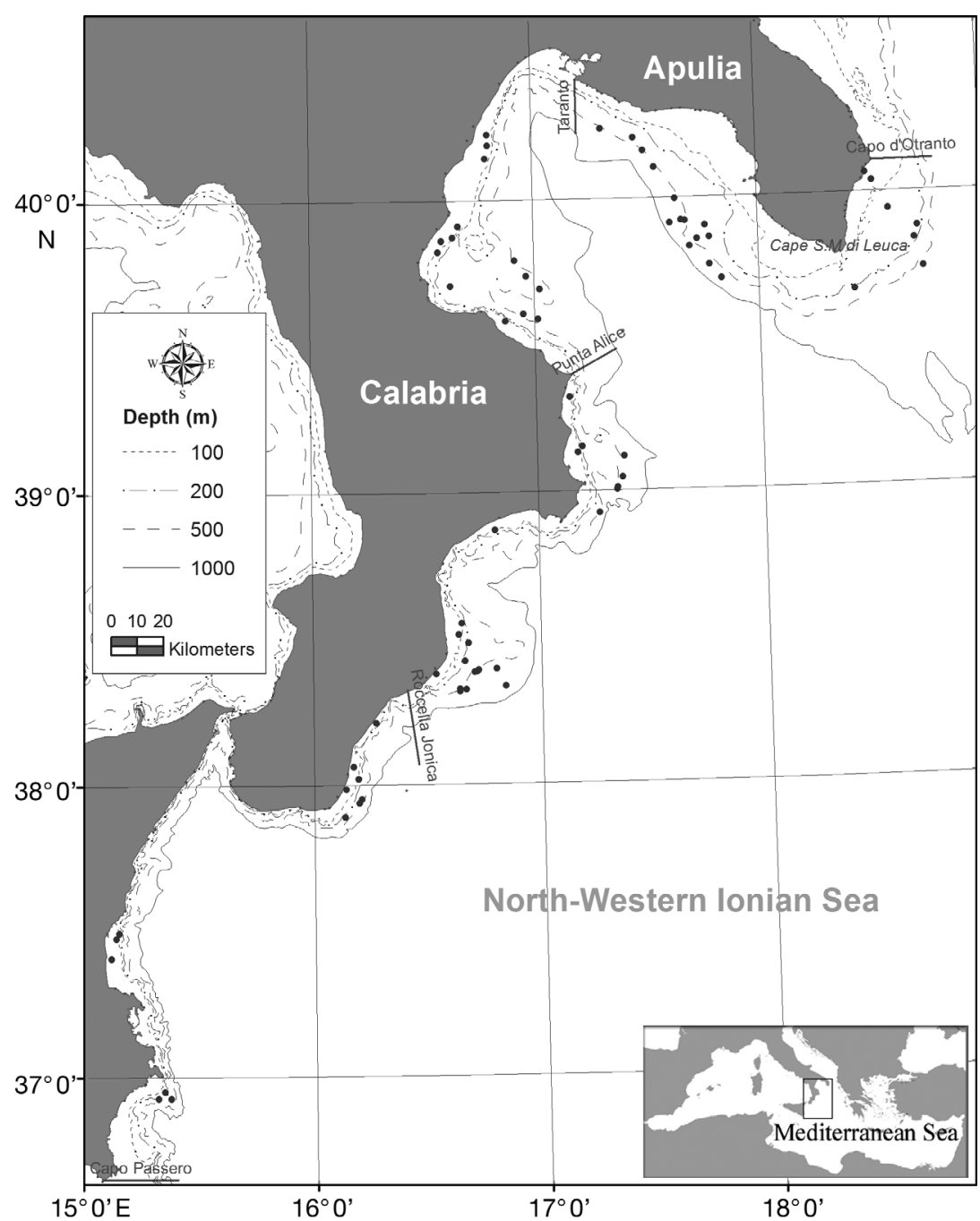

Fig. 1. North-western Ionian Sea (Central Mediterranean; FAO Geographical Sub Area [GSA] 19), indicating the spatial distribution of sampling sites (hauls, black dots) carried out during the MEDITS surveys (1995-2012). Dark solid lines delimit the MEDITS sectors in the GSA

impact on these communities, affecting a large depth range from the shelf to the slope (Maiorano et al. 2010).

\section{Data collection}

Demersal and benthopelagic community data

Data regarding demersal and benthopelagic assemblage composition, abundance and biomass were collected during the experimental trawl surveys performed in the framework of the international research project 'MEDiterranean International Trawl Survey' (MEDITS) along the time series
1995-2012 (Bertrand et al. 2000). Experimental hauls were carried out annually on the soft bottoms of the Ionian Sea according to a randomstratified sampling design in the depth range 10-800 $\mathrm{m}$. Trawl surveys carried out over 18 yr (1995-2012) were considered, including 74 hauls $\mathrm{yr}^{-1}$ in the period 1995-2001 and another 70 hauls $\mathrm{yr}^{-1}$ in the period 2002-2012. Among the over 300 species collected during the surveys, only those which occurred in more than $2 \%$ of all hauls (i.e. having a frequency of occurrence [FO] $>2 \%$ ) were considered. Moreover, 16 species belonging to the family Myctophidae, although showing an FO $<2 \%$, were grouped into a single taxon and considered in the analysis, as they represent an important prey group in the deep benthopelagic system. Furthermore, a total of 15 species of commercial interest were split into juvenile and adult taxa (Galeus melastomus, Lophius budegassa, Merluccius merluccius, Mullus barbatus, M. surmuletus, Pagellus erythrinus, Phycis blennoides, Trachurus mediterraneus, T. trachurus, Aristaeomorpha foliacea, Parapenaeus longirostris, Eledone chirrosa, E. moschata, Illex coindetii and Octopus vulgaris), in order to detect the occurrence of potential nursery areas. The analyses were carried out on the biomass standardized to the swept area $\left(\mathrm{kg} \mathrm{km}^{-2}\right)$ for 183 taxa (95 bony fish, 17 chondrichthyans, 42 decapod crustaceans and 29 cephalopods) in 1288 geo-referenced hauls.

\section{Environmental variables and fishing pressure}

At each haul position, 7 environmental variables were used to characterize the demersal and benthopelagic assemblages of GSA 19. (1) Depth (m) and (2) temperature $\left({ }^{\circ} \mathrm{C}\right)$ were measured in situ, and when missing, the temperature was obtained from the World Ocean Database of the National Oceanographic Data Center (WOD-NODC extracted using the software Ocean Data View; ODW 4.5). (3) Habitat type at haul was obtained from the MEDITS time 
series 1995-2012 and classified into 11 levels, according to Peres \& Picard (1964): Coastal Detritic (DC), Well-Sorted Fine Sand (SFBC), Muddy Detritic (DE), Coarse Sands under the influence of Bottom Currents (SGFC), Terrigenous Mud Shelf (VTC), Shelf-edge Detritic (DL), Mud Slope (VP), Soft Mud Slope (VPM), Hard Mud Slope (VPC) and ecotone zones of DC-DE and VTC-DL. Moreover, the minimum distances $(\mathrm{km})$ of each haul from (4) canyons, (5) river mouths, (6) rocky sea mounts/banks and (7) seagrass meadows (Posidonia oceanica and Cymodocea nodosa) were calculated in ArcGIS 10.x and considered as additional environmental variables. In addition to these 7 environmental variables, a fishing effort index (as the annual number of bottom otter trawling vessels in the area, FE BOT) was used in order to characterize each haul. FE BOT was derived for 15 ports in GSA 19 using the Vessel Monitoring System and the Community Fishing Fleet Register (1995-2017; http://ec.europa.eu/fisheries/fleet/index. cfm) data, as reported by Russo et al. (2017).

\section{Data analysis}

\section{SOM and cluster analysis}

The dataset was analysed by means of a SOM, which is an unsupervised iterative neural network that provides the non-linear projection and ordination of multidimensional data on a 2D map, based on multivariate similarity data (Kohonen 2001). During the iterative learning process, the original data are classified in a number of clusters, called map units, based on the Euclidean distance between the original sample and a vector associated with each map unit, and which represents the set of samples associated with its map unit (Solidoro et al. 2007). During the iterative learning process, areas (i.e. groups of vectors, with each vector representing 1 or more original samples) with similar values in many parameters (i.e. relative abundance of taxa) emerge on the $\mathrm{SOM}$, so that map units representing samples with similar relative compositions are close to each other in the 2D map space (Mazzocchi et al. 2014). Thus, at the end, the SOM represents an ordered 2D projection of a complex multi-dimensional input space.

The SOM approach has been adopted in several research fields for the purpose of pattern recognition and classification (Russo et al. 2014). In Mediterranean marine systems, SOM analyses have been applied to biogeochemical data (Solidoro et al. 2007), as well as to planktonic communities (Bandelj et al.
2008, Mazzocchi et al. 2014). The SOM technique has several advantages compared to other numerical techniques commonly used in classification or gradient analysis: SOM does not rely on any particular $a$ priori assumption about dataset structure, can efficiently cope with datasets including a reasonable number of missing data and is scarcely influenced by internal redundancy or noise (Park et al. 2003). The SOM allows identification of the characteristic patterns of continuous and dynamic processes in complex datasets containing high temporal variability, and allows a meaningful 2D model of a high-dimensional input dataset to be visualized, also by superimposition of other possible variables not used in SOM computation (Solidoro et al. 2007).

The biomass data $\left(\mathrm{kg} \mathrm{km}^{-2}\right)$ by taxa were subjected to the Hellinger transformation (Legendre \& Gallagher 2001) in order to prevent the 'double zero' problem (Legendre \& Legendre 2012), and then analysed using the SOM toolbox routines in MATLAB. The maps were built using linear initialization of map unit vectors, a sequential learning algorithm and other parameters at the default SOM toolbox values. The map units were then clustered following Ward's minimum variance method (Legendre \& Legendre 2012), and environmental variables were used for an abiotic description of the trained map. A 2-step procedure (first SOM, then clustering) allows the operator more flexibility in choosing the most appropriate trade-off between detail and compression of the information in the input dataset (Solidoro et al. 2007, Bandelj et al. 2008).

Identifying indicator species and definition of faunal groups and assemblages

After the classification, the IndVal (Dufrêne \& Legendre 1997, De Cáceres \& Legendre 2009) was applied to the original biomasses, in order to identify characteristic species in each cluster. The IndVal combines the specificity of a species in the cluster (its relative abundance), with the species fidelity (relative frequency of occurrence of the species within a given group of observations) (Dufrêne \& Legendre 1997, De Cáceres \& Legendre 2009). Species with an IndVal greater than or equal to 0.50 were considered the indicator species, representing each cluster as a faunal group or a single assemblage. As in Dufrêne \& Legendre (1997), we also calculated the maximum IndVal (IndVal Max) of each indicator species across all divisions of the dendrogram levels, in order to identify stenotopic and eurytopic species. Stenotopic 
species are indicators of only 1 group of sites (single cluster), with a small niche breadth. The IndVal of stenotopic species increases regularly or suddenly as the number of clusters increases for each division level of the dendrogram. In contrast, eurytopic species show a more or less regular decrease in their indicator value, as the sites where they are abundant are split among different site groups (more clusters), indicating a broad niche breadth (for more details, see Dufrêne \& Legendre 1997). A hierarchical structure of clusters was built through the IndVal Max, representing the distribution of the indicator species, distinguishing between stenotopic and eurytopic, within all of the assemblages of the NW Ionian Sea. Finally, the most abundant cluster among the sites aggregated in each depth layer was calculated for each year, in order to provide a representation of group dynamics in time and space. The MEDITS depth layers were considered, i.e. 0-50, 50-100, 100-200, 200-500 and 500-800 m (Bertrand et al. 2000).

Abiotic traits and calculation of diversity indices

A representative median value of environmental variables for each cluster was calculated from the samples paired with each SOM map unit (Park et al. 2003), describing the characteristic conditions, i.e. the multivariate ecological space, for the species of the cluster.

The median values (first to third quartile, minimum and maximum values) of several diversity indices, such as species richness (Margalef $d$ ), dominance (Simpson $\lambda$ ), species diversity (Shannon-Wiener $H$ ), evenness (Pielou $J$ ) (Legendre \& Legendre 2012) and average trophic levels (TLs) were computed for each identified cluster. The TL for each taxon was taken from the Mediterranean food web models and published data (e.g. Stergiou \& Karpouzi 2002).

A Kruskal-Wallis test (KW) and a non-parametric post hoc test, based on the Bonferroni-corrected pairwise Mann-Whitney test $(U)$ (Legendre \& Legendre 2012), were carried out to compare the difference between the environmental variables and biodiversity indices characterizing the clusters.

\section{Beta diversity calculations}

Beta diversity (BD), defined as the variation in species composition among the sites of a region of study (Whittaker 1972), was estimated from biomass data by calculating the variation in species composition between sites (Legendre \& De Cáceres 2013). Biomass data $\left(y_{i j t}\right)$ for $\mathrm{p}$ species $(j)$ and $\mathrm{n}$ sites (i) during $\tau$ years $(t)$ were transformed using the Hellinger transformation as recommended in the literature (Legendre \& Gallagher 2001, Legendre \& De Cáceres 2013), thus obtaining appropriate values for calculating distances:

$$
\left(y_{i j t}^{\prime}\right)=\sqrt[2]{\frac{y_{i j t}}{\sum_{j=1}^{\mathrm{p}} y_{i j t}}}
$$

The Hellinger transformed data were used to calculate the total variance of the dataset from the matrix of squared differences:

$$
S_{i j}=\left(y_{i j t}^{\prime}-\frac{\Sigma_{t=1995}^{2012} \Sigma_{i=1}^{n} Y_{i j t}^{\prime}}{n \times \tau}\right)^{2}
$$

and their sum represents the total variability in the data:

$$
\mathrm{SS}=\sum_{t=1995}^{2012} \sum_{j=1}^{p} \sum_{i=1}^{n} s_{i j t}
$$

The $\mathrm{BD}$ is then calculated as the average variability, i.e. the sum of variances across hauls and species divided by the degrees of freedom, i.e. $\mathrm{BD}=\mathrm{SS} /(\mathrm{N}-1)$.

Following the principles of BD partitioning among all possible and desirable components (see Legendre \& De Cáceres 2013), we determined the species contribution to $\mathrm{BD}$ (SCBD) and location contribution to $\mathrm{BD}$ (LCBD) as the sum of elements of variance for the locations and for the species, respectively:

$$
\begin{aligned}
\operatorname{SCBD}_{j} & =\frac{\sum_{t=1995}^{2012} \sum_{i=1}^{n} S_{i j t}}{\mathrm{SS}} \\
\operatorname{LCBD}_{i} & =\frac{\sum_{t=1995}^{2012} \sum_{j=1}^{p} S_{i j t}}{\mathrm{SS}}
\end{aligned}
$$

SCBD is high for species that in many sites present a biomass proportion significantly different from the mean proportion of all species at all sites, hence high variance. Similarly, LCBD is high for locations that include many species that are present with biomass proportion significantly different from the mean proportion of all species at all sites (Legendre \& De Cáceres 2013).

Moreover, for each site, we calculated the proportion of hauls (in the 1994-2012 period) belonging to each of the 6 clusters, thus highlighting the contribution of obtained assemblages to total BD. We also calculated the contribution of each year to total BD (YCBD) as:

$$
\mathrm{YCBD}_{t}=\frac{\sum_{j=1}^{p} \sum_{i=1}^{n} S_{i j t}}{\mathrm{SS}}
$$


a

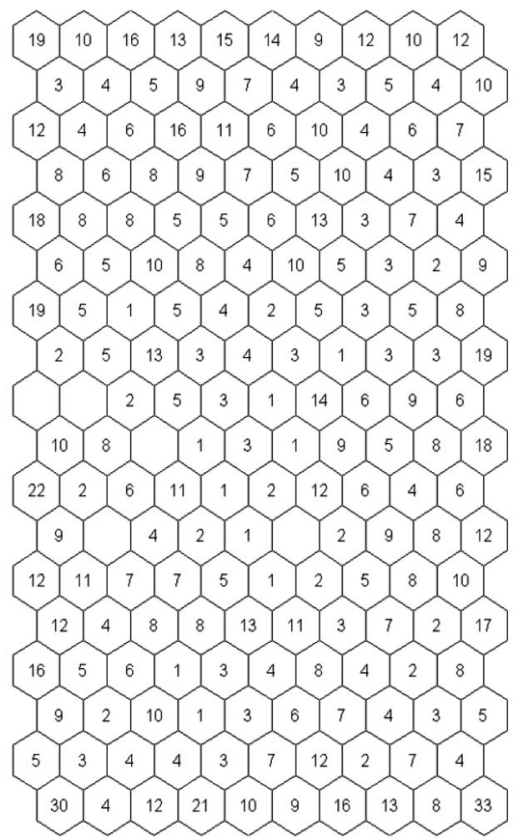

C

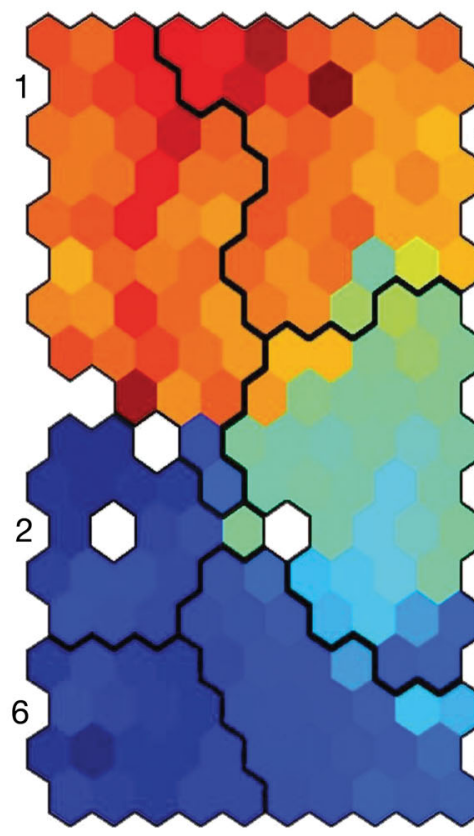

Cluster

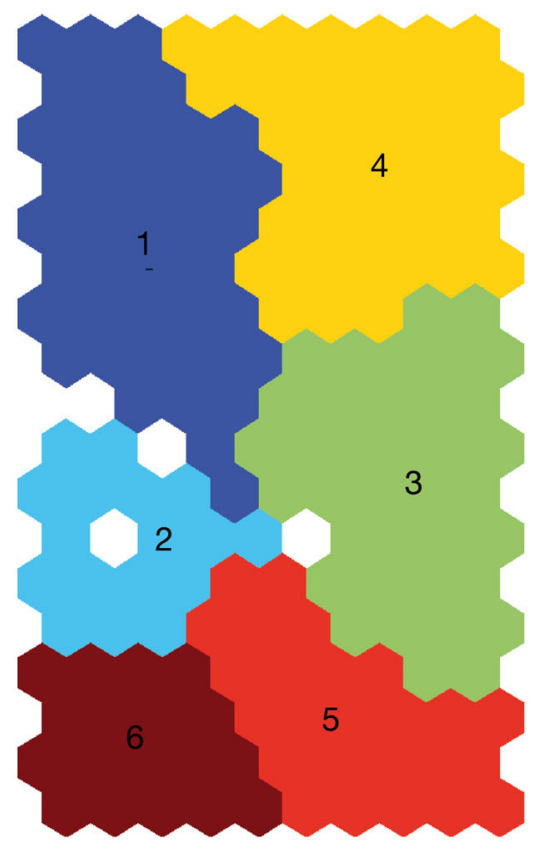

Depth $(m)$

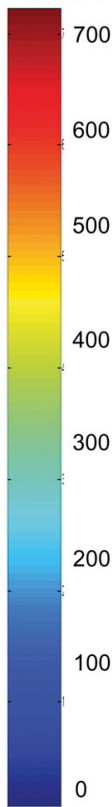

0

Fig. 2. (a) Sample density for each cell on the self-organising map (SOM). (b) Classification of 1288 sampling sites into 6 clusters (1-6) through the training of the SOM and Ward's clustering algorithm. (c) Distribution of median depth in each cell (numbers outside the SOM indicate the corresponding cluster)

ian Sea, the partitioning allows the identification of locations and species that contribute most to the regional variability that can be connected with environmental or anthropogenic drivers (Legendre \& De Cáceres 2013).

\section{RESULTS}

\section{Definition of the SOM clusters}

The SOM applied to the biomass of demersal assemblages organised the 1288 hauls into $10 \times 18$ map units, and Ward's clustering algorithm identified 6 clusters according to the similarities of species biomass (Fig. 2a,b). The largest number of samples (290) was in Cluster 1, followed by Cluster 4 (273), Cluster 3 (247), Cluster 5 (196), Cluster 6 (146) and Cluster 2 (136). In particular, Fig. 2b shows the distribution of the clusters on the SOM, and Fig. 2c shows the median depth of hauls, clearly indicating the bathymetry as a distinguishing feature of clusters. The percentage of occurrence of each cluster at the sampling sites provides a snapshot of the geographical distribution of the clusters in GSA 19 (Fig. 3).

\section{Abiotic traits associated with clusters}

Environmental and fishing variables plotted on the SOM suggest that fish assemblages are mainly influenced by bathymetry (Fig. 2c), but other variables show significant differences (Tables S1 \& S2 in the Supplement at www.int-res.com/articles/ suppl/m598p001_supp.pdf). The classification graphs are reported in

to evaluate the changes in $\mathrm{BD}$ over time, where higher YCBD indicates years with a greater contribution to the variance. In a region with an even distribution of species by site and over time, the BD contributions (i.e. SCBD and LCBD) do not show differences by species or by site. Conversely, in a system with high spatial variability, such as the NW Ion-
Fig. 4, which shows the main environmental and anthropogenic drivers describing the 6 clusters. In particular, considering the depth, significant differences occurred between all pairs of clusters except for the cluster pairs 2-6 and 4-1 (Fig. 4). The results highlight the distribution of Clusters 2 and 6 on the coastal shelf, Cluster 5 in the shelf-break zone, Clus- 

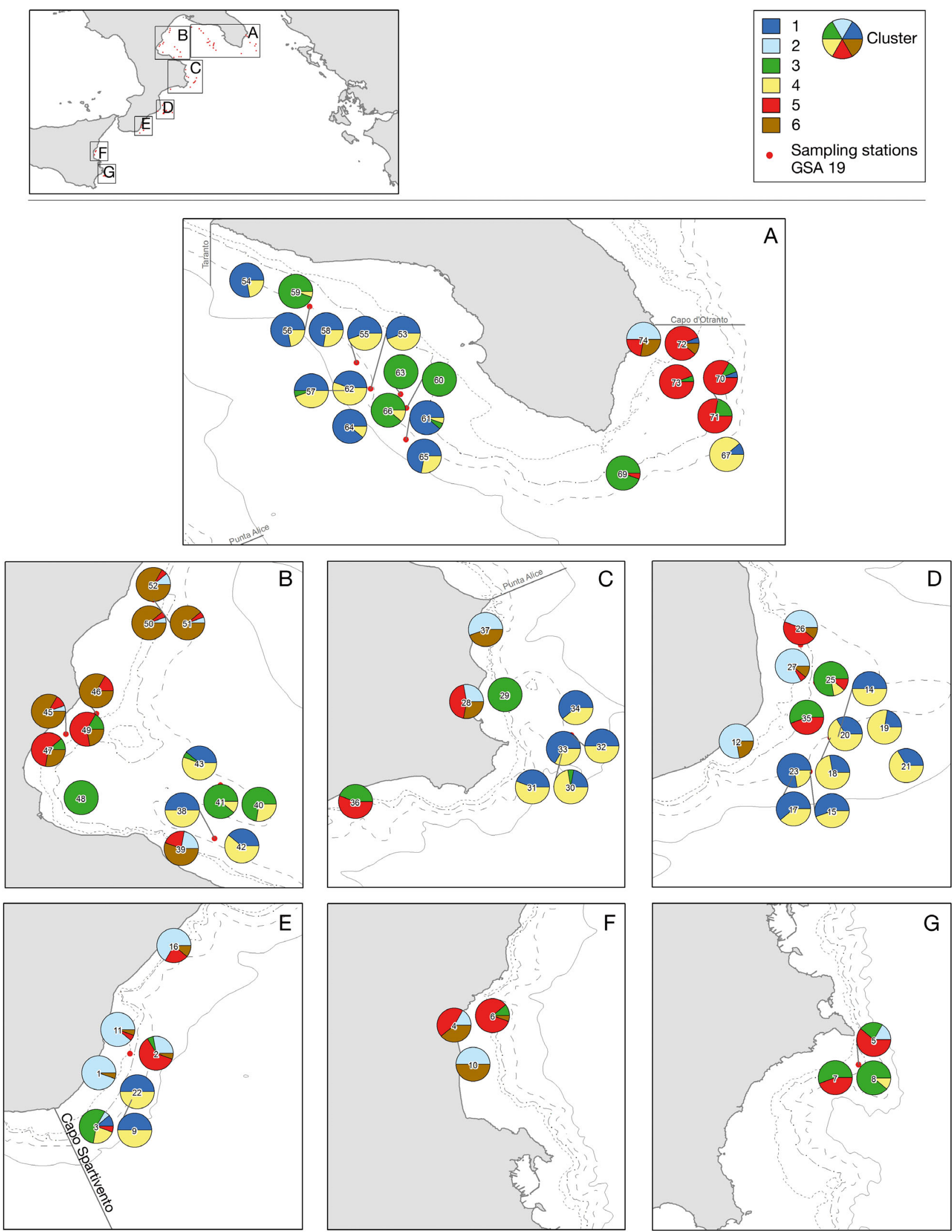

Fig. 3. Composition of each sampling site in terms of cluster occurrence in the FAO Geographical Sub Area (GSA) 19 over the time series 1995-2012. Numbers in pie charts indicate the sampling site 


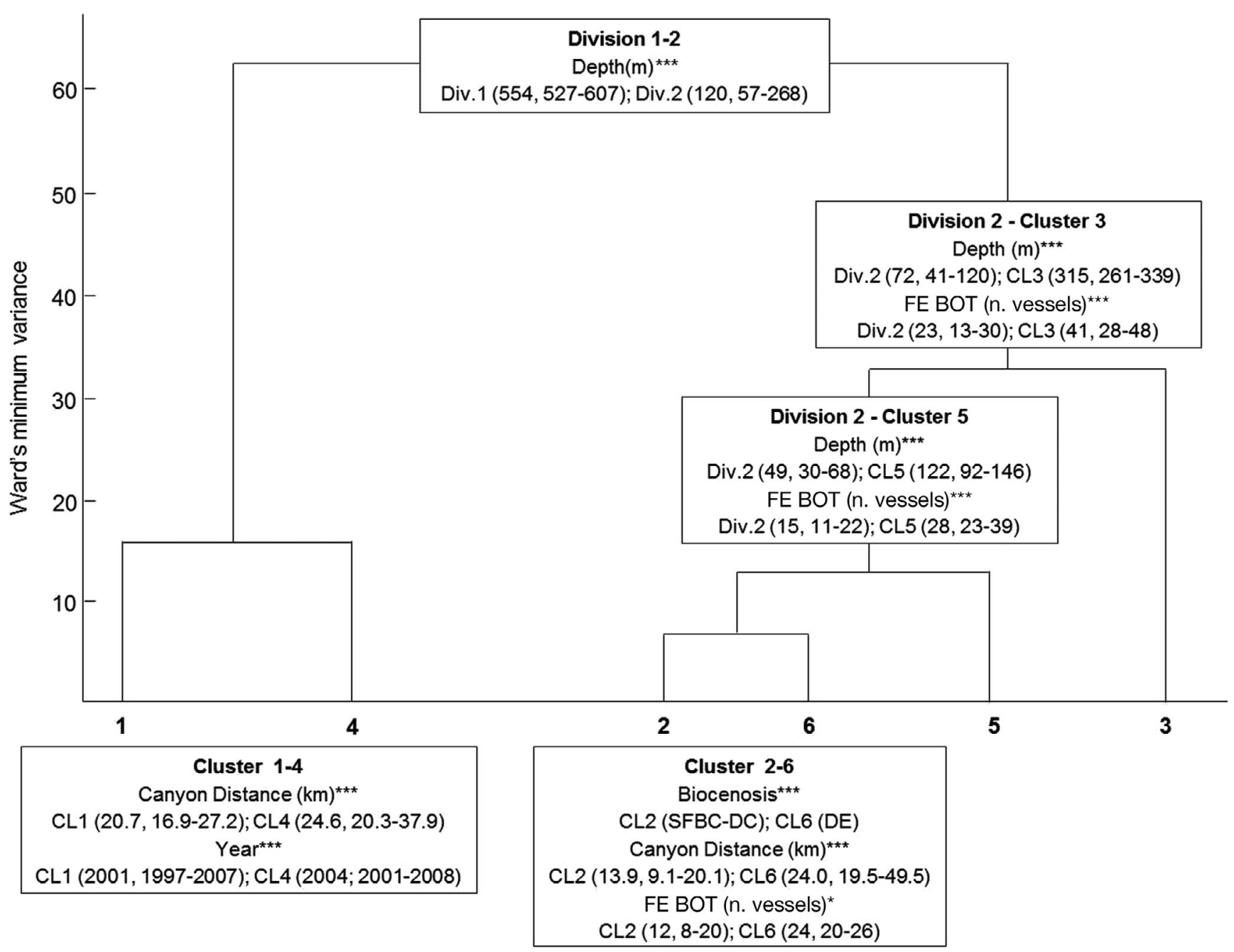

Fig. 4. Main significant differences (Mann-Whitney pairwise Bonferroni-corrected test; $\mathrm{p}<0.05$ ) between environmental variables of clusters identified by the self-organising map (SOM). The median value and interquartile range for the variables reported in the clusters are in brackets. Only significant differences are reported, with ${ }^{*} p<0.05,{ }^{* *} p<0.01$ and ${ }^{* * *} p<0.001($ see Table S1 in the Supplement for complete results). FE BOT: fishing effort (bottom otter trawling vessels)

ter 3 on the upper slope and Clusters 1 and 4 in slope areas $(p<0.05)$. The temperature showed the same pattern of depth (Table S1). The distance from canyons was the lowest in Cluster 2, thus being the variable differentiating it from the other coastal shelf cluster (Cluster 6). Similarly, the distance from canyons of sampling sites belonging to Cluster 1 was significantly lower than in Cluster $4(p<0.05)$, thus effectively explaining the separation between the 2 slope clusters (Fig. 4). The distance from rocky mounts and banks was the lowest for sampling sites in Cluster $6(\mathrm{p}<0.001)$.

Considering the habitat types, DC and SFBC were the most frequent in Cluster 2, with a frequency of occurrence of $3.1 \%(p<0.05)$ and $1.8 \%(p<0.05)$, respectively. DE occurrence was highest in Cluster 6 (frequency of occurrence of $4.2 \%, \mathrm{p}<0.001$ ). In
Cluster 5, VTC and VTC-DL showed highest occurrences of $6.8 \%(p<0.05)$ and $3.8 \%(p<0.001)$, respectively. In Cluster 3, the occurrence of VPM was highest $(14.4 \%, \mathrm{p}<0.001)$. VPC occurrence was highest in Cluster $4(13.2 \%, \mathrm{p}<0.05)$ and Cluster 1 (16.6\%, p < 0.05).

The FE BOT showed an increase in median values of the vessels along the bathymetric gradient, identifying 3 different fishing areas: coastal shelf area (Clusters 2 and 6), shelf break area (Cluster 5) and deep area (Clusters 3, 4 and 1). In the coastal shelf, a low significant difference was observed between the clusters, with the median value of 24 vessels being higher in Cluster 6 than Cluster 2 ( $<<0.05)$. In the shelf break zone, the median value of 28 vessels was significantly different from coastal areas $(\mathrm{p}<$ $0.001)$ and deep areas $(p<0.05)$. Deep areas were 
represented by the upper slope (Cluster 3) and slope (Clusters 4 and 1), with median values of 41, 32 and 35 vessels, respectively, with no significant differences between them.

\section{Indicator species, faunal groups and diversity patterns}

In total, IndVal identified 71 indicator species as characteristic species of clusters (Table S3). In the coastal shelf zone, Cluster 2 was mainly characterized by the presence of demersal species, such as Mullus barbatus, Spicara flexuosa, Pagellus acarne, Boops boops and P. erythrinus, defining this cluster as the Coastal Demersal Group. The shallow hauls in Cluster 6 showed a mixed association of indicator species, with benthopelagic and benthic taxa more abundant, and it was thus defined as the Coastal Benthopelagic Group. In particular, Liocarcinus depurator, Engraulis encrasicolus and Chelidonichthys lucerna were the main indicator species. The main indicator species in Cluster 5 were Trachurus trachurus, juveniles and adults of Illex coindetii and Merluccius merluccius, Aspitrigla cuculus, Glossanodon leioglossus and adults of Lophius budegassa, representing the Shelf Break Group. On the upper slope, the largest number of indicator species (25) was identified in Cluster 3 corresponding to the Epibathyal Group, including Parapenaeus longirostris, Plesionika heterocarpus, Micromesistius potassou, Munida iris and juveniles of Phycis blennoides. On the slope, Clusters 4 and 1 showed a different composition of indicator species. The former was mainly characterized by demersal fauna, such as Galeus melastomus, Hoplostetus mediterraneus, Plesionka martia, macrourids (Nezumia sclerorhynchus, Hymenocephalus italicus, Caelorhynchus caelorhynchus), adults of $P$. blennoides and juveniles and adults of Aristaeomorpha foliacea, representing the Bathyal Demersal Group. In the latter, Aristeus antennatus, Lampanictus crocodilus, Notacanthus bonapartei, Pashipaea multidentata, Chauliodus sloani and Stomias boa boa were the main indicator species belonging to benthopelagic fauna, thus defining Cluster 1 as the Bathyal Benthopelagic Group.

The classification of stenotopic and eurytopic species showed the membership degree of indicator species to the 6 clusters and all division levels of the dendrogram, as identified by means of the IndVal Max (Fig. 5). In the Coastal Demersal Group, the stenotopic species were Arnoglossus thori and Pagellus acarne, while Liocarcinus depurator and bentho- pelagic fauna (mainly E. encrasicolus and Sardina pilchardus) were the stenotopic species of the Coastal Benthopelagic Group. The stenotopic species in the Shelf Break Group were the juveniles of I. coindetii and M. merluccius, Aspitrigla cuculus and G. leioglossus. The indicator species in the Epibathyal Group were all stenotopic species of the upper slope. In the Bathyal Demersal Group, C. caelorhynchus and juveniles of $A$. foliacea were detected as stenotopic species, while $C$. sloani and $S$. boa boa were identified in the Bathyal Benthopelagic Group. Taking into account the eurytopic species classification, several indicator species showed membership in different clusters (Fig. 5). In the Shelf-Epibathyal Division (Clusters 2, 3, 5 and 6) species with a distribution from the coastal area to the upper slope were detected, such as L. budegassa and the adults of $I$. coindetii and $M$. merluccius. In the Bathyal Division (Clusters 1 and 4), several species were associated with both bathyal groups, such as N. sclerorhynchus, Plesionka martia, the bathyal sharks (Etmopterus spinax and G. melastomus), Hoplostetus mediterraneus, Hymenocephalus italicus, adults of P. blennoides and A. foliacea, A. antennatus and L. crocodilus. The main eurytopic species detected in the Coastal Shelf-Shelf Break Division (Clusters 2, 5 and 6) were M. barbatus, Spicara smaris, Boops boops, P. erythrinus, O. vulgaris and C. lucerna.

According to the KW test, each cluster showed significant differences for all biodiversity indices $(\mathrm{p}<$ 0.001; Table S2, Fig. 6a-d) and different presence of functional traits (Fig. S1 and Table S3). Cluster 3 showed the highest significant indices values, except for the Pielou index $(\mathrm{p}<0.001)$. Considering the shallowest clusters, all indices in Cluster 2 were significantly higher than in Cluster 6 ( $p<0.001)$. On the slope, the Margalef and Shannon-Wiener indices were higher in Cluster 4 than Cluster 1, while the Simpson index was higher in Cluster 1 than Cluster 4 $(p<0.001)$. Finally, significant differences were observed between the shallowest hauls (Clusters 2 and 6) and shelf break hauls (Cluster 5), with higher values of the Margalef, Simpson and Shannon-Wiener indices detected in the shelf break zone $(p<0.05)$. The Shelf Break Assemblage showed the highest TL (3.86), while the Coastal Demersal Group and Epibathyal Group had the lowest TL (3.30-3.32; Fig. 6e).

\section{Analysis of BD}

The overall total BD for the NW Ionian Sea was calculated as 0.79 (Fig. 7). The hauls ordered by 


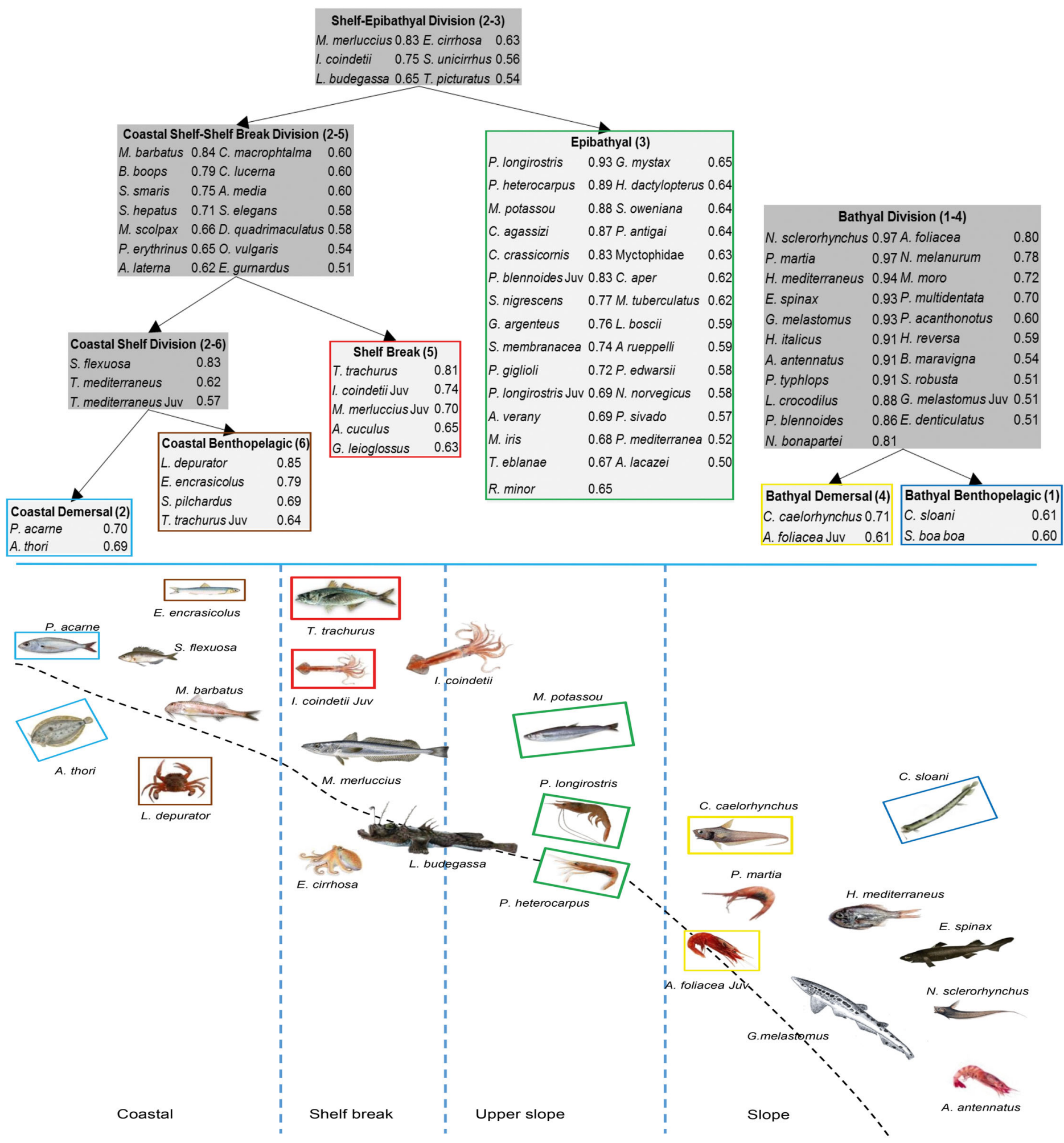

Fig. 5. Hierarchical structure in the demersal and benthopelagic assemblages described by indicator species: stenotopic (coloured boxes) and eurytopic (dark boxes). The maximum indicator value index (IndVal Max) value is reported to the right of the species, while the clusters are indicated after the group name. The main stenotopic and eurytopic species are represented in the scheme with the depth gradient (black dashed line) and the marine domains (vertical blue dashed lines). Stenotopic species are shown in coloured boxes corresponding to the clusters, while the eurytopic species are not in boxes. Full species names are given in Table S3 in the Supplement; Juv = juveniles 

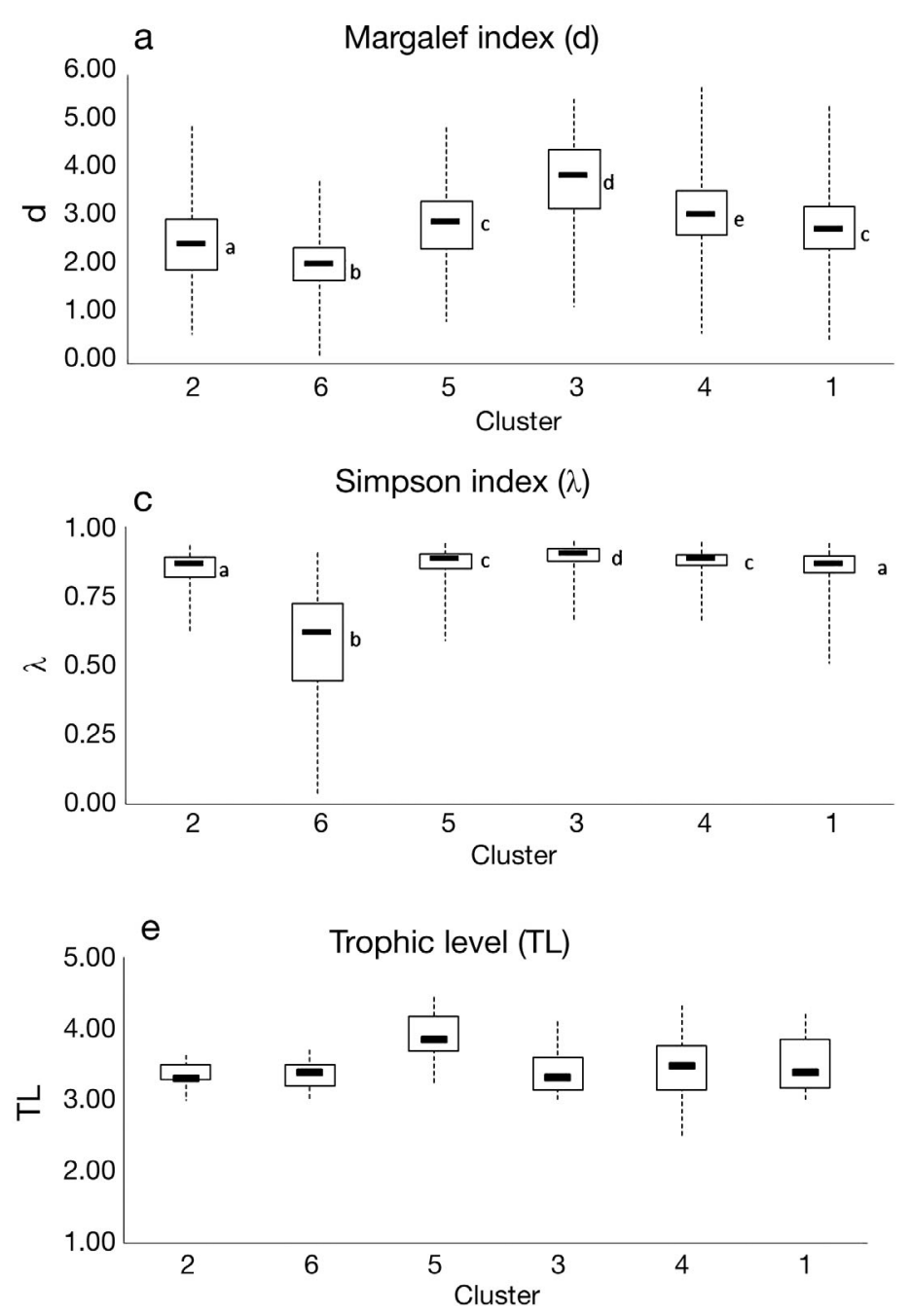

decreasing order of contribution to BD (LCBD; vertical array in Fig. 6) revealed that the contributions to $\mathrm{BD}$ ranked highest for Cluster 2, followed by Clusters 6, 5, 3, 4 and 1, thus showing a pattern related to depth. Conversely, the contribution of species to BD (SCBD, the horizontal array in Fig. 6 reports the first 31 species with the highest contribution to $\mathrm{BD}$ ) indicated that $A$. antennatus, $G$. melastomus, $M$. merluccius, $H$. mediterraneus and $L$. depurator made the greatest contributions to $\mathrm{BD}$. Inspection of BD contribution by species and haul (central matrix, only species with $\mathrm{SCBD}>75^{\text {th }}$ percentile) highlights the species characterizing and contributing to the BD of clusters, namely $A$. antennatus, which proved to be the major contributor for the BD of Cluster 1, M. barbatus for Cluster 2, $P$. longirostris for Cluster 3, G. melastomus and $H$. mediterraneus contributed importantly to the BD of Cluster 4, G. leioglossus to Cluster 5 and L. depurator for Cluster 6. Analysis of YCBD highlights a
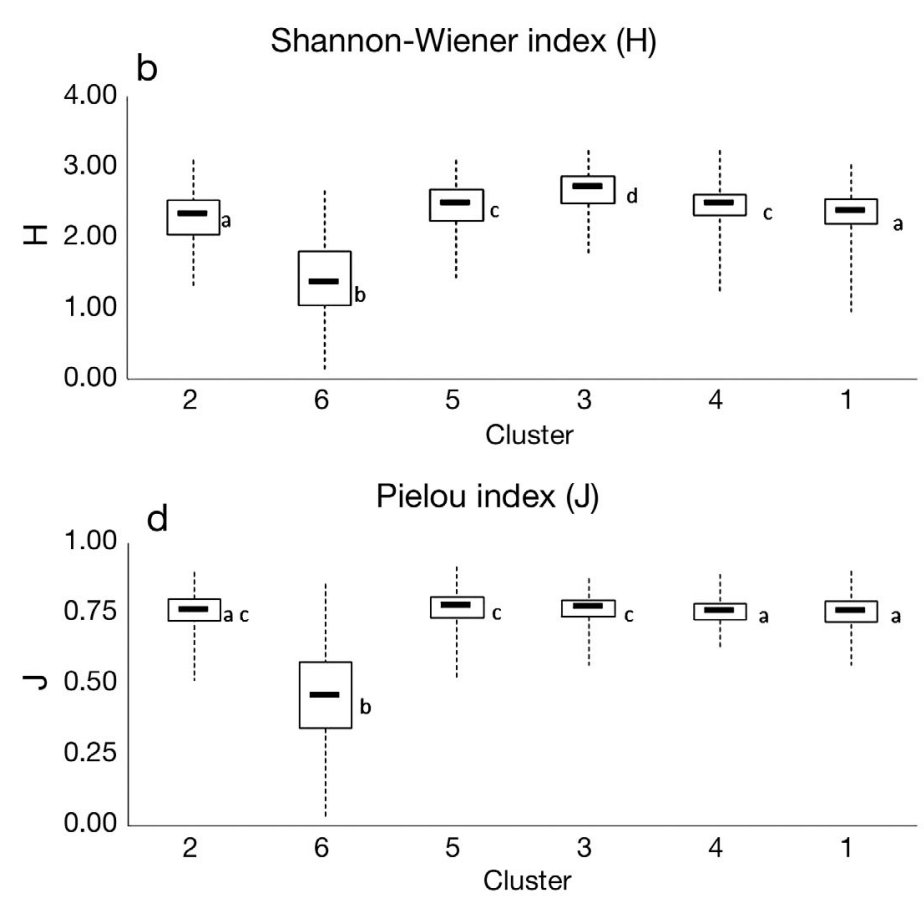

Fig. 6. (a-d) Diversity indices and (e) trophic level for each cluster, ordered from the shallowest to the deepest. Midline: median; box limits: quartiles; whiskers: minimum and maximum values. Different letters beside the box plots indicate significant differences in diversity indices between clusters based on the Mann-Whitney pairwise Bonferronicorrected test $(U, \mathrm{p}<0.05)$. The complete results of significant differences are reported in Table S2 in the Supplement

consistent decrease in $\mathrm{BD}$ over time at a rate of $0.7 \% \mathrm{yr}^{-1}$ (Fig. 8a), with a clear change in the occurrence of coastal and bathyal groups starting in 2000 (Fig. 8b and Fig. S2) and coinciding with an increase in temperature (Fig. 8c). The most relevant changes were observed for Clusters 2, 6, 5, 4 and 1 at the $0-50,50-100$ and 500-800 m depth layers (Fig. 8b).

\section{DISCUSSION}

The analysis of demersal and benthopelagic assemblages of the NW Ionian Sea led to the identification of 6 clusters in which the assemblages can be aggregated over space and time. The clusters, obtained without a priori assumptions and exclusively using biomass data by species and by haul on the SOM, were described with indicator species and environmental features. 


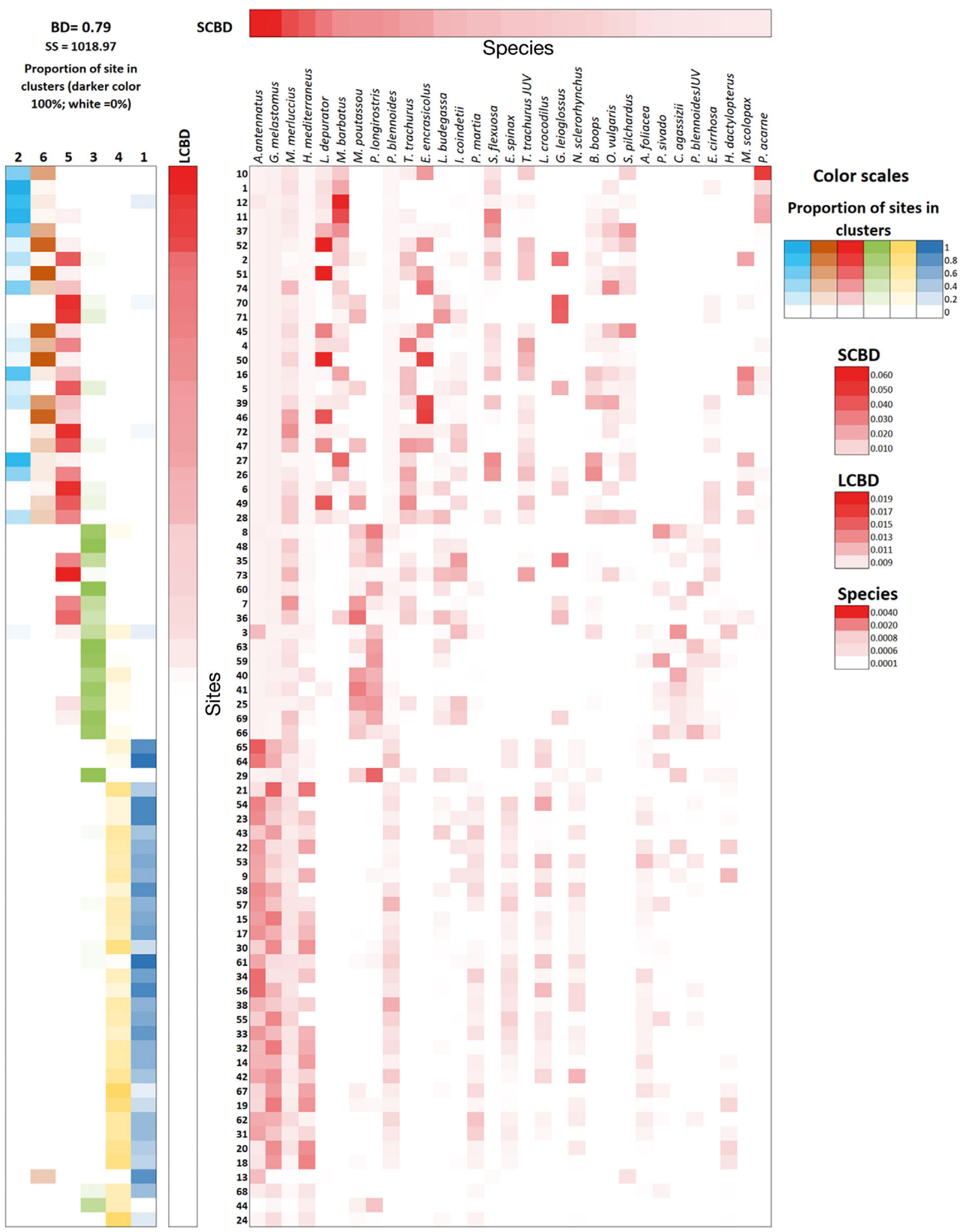

Fig. 7. Analysis of beta diversity (BD) for the MEDITS data in the north-western Ionian Sea (1995-2012). Contribution of each species in each haul to total BD $(\mathrm{BD}=0.79)$ is represented in the central matrix. Species are ordered by their decreasing contribution to BD (SCBD vector), and only species with BD greater than average are shown (first 31 species). Locations (hauls) are ordered by decreasing contribution to local BD (LCBD). Left matrix indicates the number of replicates of the haul (in the period 1994-2012) belonging to the 6 clusters 


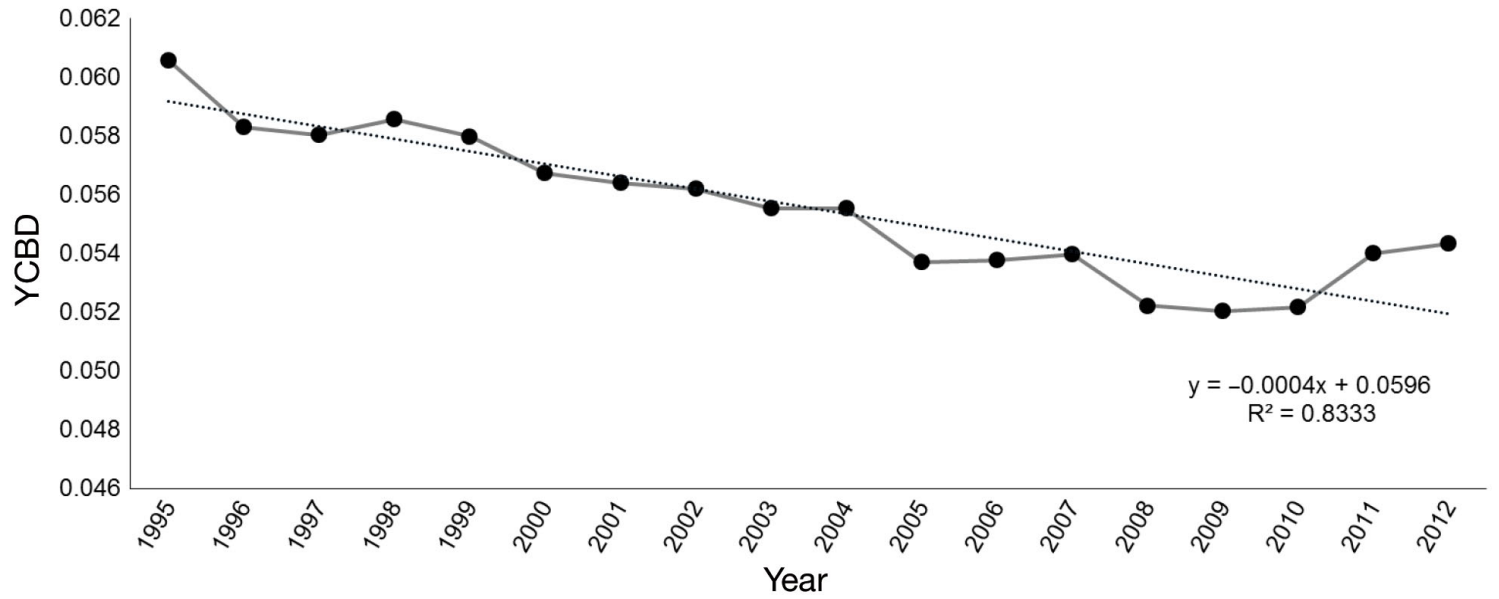

b Cluster: \begin{tabular}{|l|l|l|l|l|l|l|}
\hline & 2 & 3 & 4 & 5 & 6 & $\mathrm{~V}$ \\
\hline
\end{tabular}

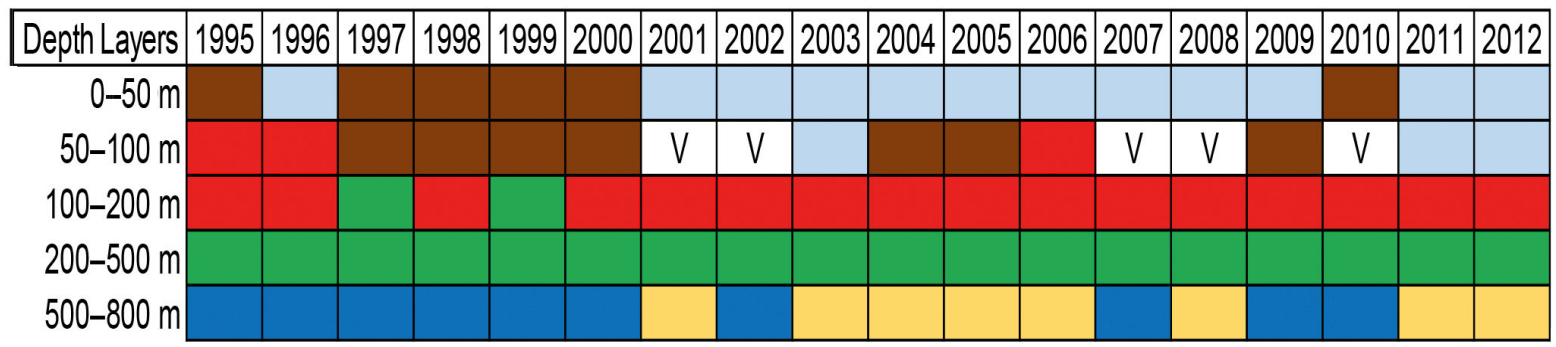

c

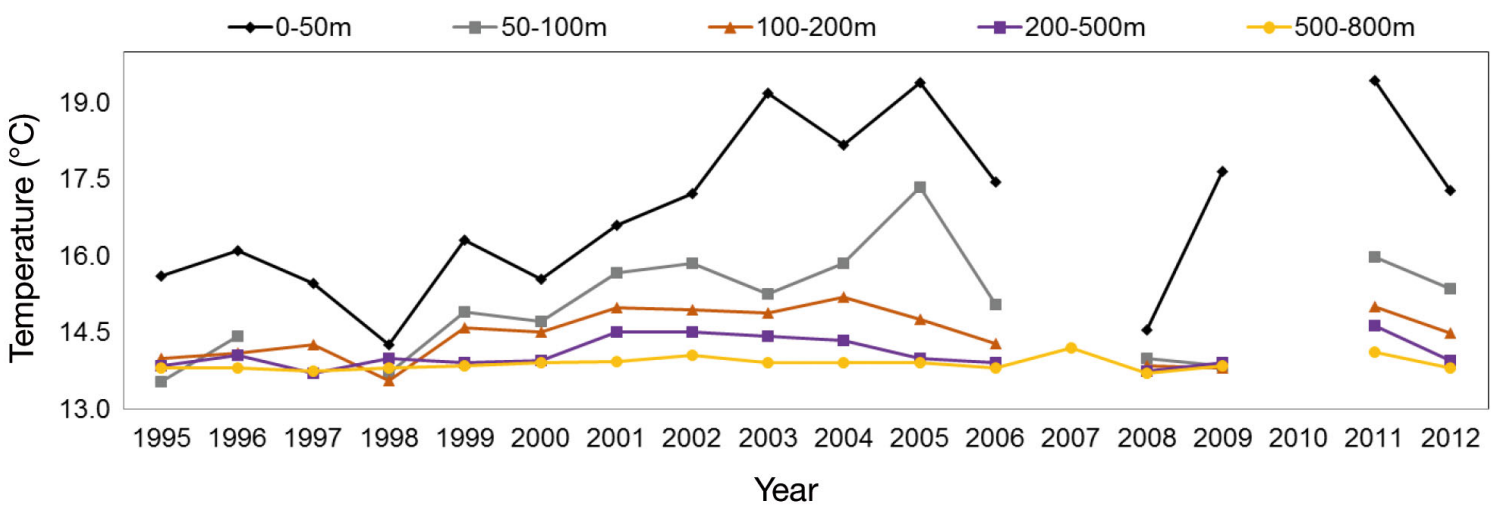

Fig. 8. (a) Contribution to total beta diversity (BD) during the sampling years (YCBD) shows a remarkable decline over time. (b) Distribution of the most abundant clusters in time and depth layers. ' $\mathrm{V}$ ' indicates that the clusters are present in equal numbers. (c) Median values of temperature along time series obtained by sampling sites aggregated in depth layers

\section{Faunal groups of NW Ionian Sea assemblages and abiotic traits}

In the shelf area, the Coastal Demersal Group and the Coastal Benthopelagic Group showed a clear distinction affected by a series of environmental and fishing factors. The association of stenotopic species (Pagellus acarne and Arnoglossus thori) of the Coastal Demersal Group with SFBC and DC habitat types has previously been observed in other shelf demersal assemblages at the Mediterranean scale (Colloca et al. 2003, García-Rodriguez et al. 2011). The Coastal Benthopelagic Group seems to be associated with muddy bottoms, with DE as the prevalent habitat type and Liocarcinus depurator as the indicator species (García-Rodriguez et al. 2011). Moreover, Engraulis encrasicolus and Sardina pilchardus were identified as indicator species for this group, and this can be linked to muddy habitats, since several studies have provided evi- 
dence of the influence of freshwater on the spawning area distribution of these species (e.g. Lloret et al. 2004). The high variety of habitat types in the Coastal Demersal Group (sand, coastal detritic, muddy detritic) increases the heterogeneity of habitats and the availability of ecological niches, explaining the higher values of biodiversity indices in this cluster. The 2 coastal clusters (2 and 6) are significantly different in their distance from canyons (Fig. 4), which could influence the transport and sinking of muddy sediments in the deep bottoms (Puig et al. 2000), thus affecting the habitat variety in shelf areas. The difference in the fishing effort between the 2 clusters could be explained by the localization of Cluster 2 at depths less than $50 \mathrm{~m}$, the depth limit of trawling activity ruled by the European fishing policy (EC 2006). In contrast, the hauls aggregated in Cluster 6 were distributed over $50 \mathrm{~m}$ of depth, where the occurrence of commercial species (Chelidonichthys lucerna, Mullus barbatus, Pagellus erythrinus) classified as indicator and eurytopic species in the area, could explain the low biodiversity and species richness on these grounds, which are only slightly impacted by trawl fishing.

Previous local studies explored the demersal assemblage in the NW Ionian Sea at depths between 200 and $700 \mathrm{~m}$ (D'Onghia et al. 1998, 2003), while our work, by investigating the depth range $10-800 \mathrm{~m}$, permitted the identification of a Shelf Break cluster. This was identified as a specific assemblage distinct from the coastal shelf and upper slope at an average depth of $122 \mathrm{~m}$ and shows specific environmental traits and species composition, as reported in other studies (Colloca et al. 2004, García-Rodriguez et al. 2011). In particular, these areas are characterized by high primary production, being important feeding grounds for several species (Colloca et al. 2004), as suggested by the co-occurrence of juveniles and demersal top predators. This was also observed for juveniles of the commercial species Merluccius merluccius, identified as an indicator species, confirming that these areas are possible nursery grounds (Carlucci et al. 2009a). Furthermore, the species classified as eurytopic in the Coastal Shelf-Shelf Break Division seem to influence the assemblage structure through several patterns of trophic guilds (Colloca et al. 2010). The distinction between juveniles and adults of $M$. merluccius as stenotopic and eurytopic, respectively, reflects the ontogenetic shift in their diet affected by the changes in the habitat distribution of the species (Carpentieri et al. 2005).

The deep grounds in the NW Ionian Sea are structured in upper slope and slope, with a transition from
Epibathyal to Bathyal groups driven by the bathymetric gradient (D'Onghia et al. 1998, 2003). Our results confirm the existence of this boundary, adding the influence of habitat type to the assemblage structure, with the change from VPM to VPC. The upper slope is characterized by a high number of indicator species distributed at depths of 300-400 m, with a high occurrence of decapod crustaceans (Capezzuto et al. 2010). Very interestingly, the results of the biodiversity indices highlight the occurrence of an edge effect on the species richness and diversity going from shelf break to upper slope with the highest values detected in the Epibathyal group. Taking into account the eurytopic species associated with shelf and upper slope grounds, top predators characterized by a wide range of depth displacement, such as Lophius budegassa, were detected (Carlucci et al. 2009b).

On the slope, cluster separation was marked by the distance from submarine canyons and temporal changes. In accordance with the literature, submarine canyons affect the structure and composition of the deep macrofaunal community, influencing sediment and nutrient transport processes as well as plankton production, which is the main food resource for the benthopelagic and demersal fauna (Ramirez-Llodra et al. 2010, Fernandez-Arcaya et al. 2017). The temporal changes in the occurrence of bathyal groups could be linked to EMT effects (Fig. 8b,c and Fig. S2), as detailed below. Together with the environmental factors, the 2 groups seem to be distinct in the different functional traits of the indicator species (feeding habits, reproduction cycles, ontogenetic shift). At the same time, most indicator species being classified as eurytopic suggests the coexistence of both groups in a complex bathyal assemblage thanks to the relative stability of environmental conditions in the deepest waters (D'Onghia et al. 2004). In fact, the Bathyal Benthopelagic Group is characterized by indicator species mostly classified as eurytopic performing vertical migrations, and only 2 stenotopic species (Chauliodus sloani and Stomias boa boa), which exhibit bathypelagic behaviour with active predation on meso-bathypelagic prey (Butler et al. 2001). The association of Aristeus antennatus with the bathyal benthopelagic group could be explained by its capacity for daily vertical displacements (Relini et al. 2000). Similarly, the Bathyal Demersal Group was mainly represented by demersal and benthodemersal fauna, with only 2 stenotopic species: Caelorhynchus caelorhynchus and the juveniles of Aristaemorpha foliacea, which are characterized by 
feeding habits linked to infaunal and epibenthic prey (Madurell \& Cartes 2006, Kapiris et al. 2010). Nezumia sclerorhynchus, Hymenocephalus italicus, Galeus melastomus, Hoplostetus mediterraneus and Plesionka martia represent the main indicator species in the group, exhibiting a eurytopic habitus, likely to be due to their feeding behaviour: $G$. melastomus is a generalist predator of epibenthic and benthopelagic species (Carrassón et al. 1992), $H$. mediterraneus feeds on suprabenthic and benthopelagic prey (Madurell \& Cartes 2005), and $P$. martia is an active predator on macrozooplankton and benthic resources (Cartes 1993), with a population in the NW Ionian Sea structured in an ontogenetic pattern and depth distribution as reported by Maiorano et al. (2002). Similarly, N. sclerorhynchus and $H$. italicus were grouped with eurytopic species, exhibiting pelagic and suprabenthic diets (Madurell \& Cartes 2006). The separation between the bathyal assemblage of juveniles and adults of A. foliacea as stenotopic and eurytopic species, respectively, is interesting and consistent with the ontogenetic shift in the diet (Kapiris et al. 2010).

Considering the fishing effort, no difference was observed between epibathyal and bathyal assemblages, which represent the main fishing grounds in the NW Ionian Sea. Most fishing resources are represented by Parapenaeus longirostris on the upper slope and A. foliacea and A. antennatus on the slope, with higher levels of exploitation associated with $P$. longirostris (Maiorano et al. 2010, Russo et al. 2017).

The combination of canyon effects and the impacts of fishing activities are most likely to have shaped the biodiversity and community composition of these habitats (Ramirez-Llodra et al. 2010). However, with the available information it is only possible to roughly disentangle the role of environmental and fishing factors in distinguishing between the 2 clusters. The interpretation of bathyal clusters is given by the indicator species, stressing the importance of the SOM and IndVal combination in the analysis.

\section{Spatio-temporal patterns and BD}

The BD results summarise a patchy distribution of habitats, the variability of environmental factors and fishing pressures resulting in a complex environmental system for the NW Ionian Sea. The results highlight that large contributions to BD are due to bathymetric differences in the NW Ionian Sea. Highly variable hydrodynamic and environmental conditions characterize the coastal shallow areas, which thus result in high patchiness and high variability of spatial diversity. This explains the high contribution of coastal clusters ( 2 and 6 ) to regional BD. Notably, the highest contribution to BD was from sites belonging to Cluster 2 (Coastal Demersal Group, see LCBD), which was also characterized by a high variety of habitat types. In bathyal areas, benthopelagic and demersal groups (Clusters 1 and 4 , respectively) are subject to much more stable conditions, resulting in a lower contribution to BD for sites in these areas. Nevertheless, sites belonging to Cluster 1 are generally ranked higher in terms of LCBD than those belonging to Cluster 4, which can be related to the proximity to canyons of the former. Fisheries pressure might also induce variability, thus influencing BD since a higher ranking for LCBD was observed for grounds characterized by the Coastal Demersal Group, occurring at depths $<50 \mathrm{~m}$, which shows a significantly lower fishing pressure than areas inhabited by the Coastal Benthopelagic Group. The fishing impacts on bathyal groups (Clusters 1 and 4) are harder to understand, because these clusters are characterized by similar fishing effort. However, the higher LCBD in the area inhabited by the Bathyal Benthopelagic Group could be supported by the 'refuge effect' of submarine canyons (Fernandez-Arcaya et al. 2017), and by the low impact of trawling activities on benthopelagic species that characterize this group. Further analyses might be required, however, to understand the influence of fishing pressure on $\mathrm{BD}$ compared to that of canyon proximity. Similarly, more work is needed to understand whether fishing pressure has a different influence on the basis of depth, i.e. if it shows increasing patchiness in coastal areas and increasing homogeneity in deep areas.

The species contribution to BD within the clusters shows an interesting overlap with the main indicator species identified by the IndVal. In some cases, the contribution of species to BD seems to be driven by their high abundance in the clusters (thus high IndVal), such as $A$. antennatus in the bathyal assemblage, or in other cases by specific relationships with habitats, such as L. depurator in the Coastal Benthopelagic Group characterized by DE. The combination of species abundance and frequency of occurrence at the sites computed by the IndVal (Dufrêne \& Legendre 1997) supports the overlap of results with BD, where the only abundant species regularly occurring at the sites are the indicators in each cluster and rank high in the contribution to BD. 
The decrease over time of the $\mathrm{BD}$ contribution (YCBD) is robust because sampling gear and sampling sites were not changed as defined in the MEDITS protocol (Bertrand et al. 2000), and the number of sampling sites, although changing from 74 in the period 1995-2001 to 70 sites in 2002-2012, was found to be irrelevant to the trend identified. Conversely, the observed decrease in the bathyal benthopelagic group, which started at the end of the 1990s (see Fig. S2), could still represent a possible explanation for the trend in BD over time (Fig. 8a). The dynamics of bathyal assemblages in the Ionian Sea are affected by changes linked to the EMT, which showed an inversion of circulation at the end of the 1990s (Civitarese et al. 2010). The changes are confirmed by the temporal group dynamics along the bathymetric gradient, where the temperature seems to be a relevant driver in the assemblage dynamics (Fig. 8b,c). Many observations made at the dynamic population level for several species (e.g. A. foliacea and $A$. antennatus) have shown a significant response to the environmental changes connected to EMT (Capezzuto et al. 2010, D'Onghia et al. 2012a). Important changes also seem to have occurred in the same period in the coastal groups, with a high occurrence of the coastal benthopelagic group up to 2000, likely due to the phytoplanktonic bloom which occurred in the same period (D'Ortenzio et al. 2003). Therefore, the causes of the trend in variance of the sample seems to be related to biological phenomena, which are admittedly difficult to disentangle and might require further work and additional information (e.g. data on changes in fishing effort over time).

\section{Usefulness of results}

The analysis of indicator species by cluster has highlighted the possibility of using such species as flagships or at least as indicators for the entire assemblage. The distinction between stenotopic and eurytopic species evaluates the degree of membership of a species to 1 or more habitat, providing the basis for future studies on the food web relationships between different faunal groups or assemblages. The analysis of the average environmental and fishing variables related to the hauls aggregated into clusters has provided evidence of the ecological reasons behind the classification and of the recognition pattern achieved by the SOM. According to BD, the clusters describe the contribution of different assemblages to the subregional diversity, highlighting how the ecological patterns are affected by species composition, envi- ronmental and fishing factors, as well as their temporal dynamics.

The analyses reported here represent preliminary phases for identification and characterization of species aggregations before modelling marine trophic webs. Species composition, environmental factors and key species characterizing the clusters highlight that these represent well-defined assemblages in space and time. Thus, these aggregations could be considered as units within which to identify functional groups useful in the framework of spatial modelling of marine food webs and ecosystems (e.g. Ecospace or Atlantis, Plaganyi 2007, Grüss et al. 2018). Furthermore, the use of aggregation species for the assessment of the marine food web state, which is required by Descriptor 4 of the EU Marine Strategy Framework Directive (MSFD) (Tam et al. 2017), and the indicator of species importance (such as IndVal) could be a sound method for the recognition of the most important species groups in a community to be used as indicators. These groups might be treated as surveillance indicators of food web changes (sensu Shephard et al. 2015) and thus used to identify the environmental status of the framework of the MSFD (EC 2008).

\section{CONCLUSIONS}

The structure, distribution pattern and temporal dynamics of demersal assemblages have been characterized with environmental variables across a multiple spatial scale using SOM, clustering methods, the IndVal index and analysis of BD. The ranking of species importance inside the group allowed us to explore the assemblage from 2 points of view: the first considered the species aggregation defined by the biomass and temporal occurrence, and the second considered the position of individual species with respect to their habitat association. The set of these analytic tools showed sensitivity in the pattern recognition of the species groups composing the assemblage through environmental variables and ecological traits of indicator species. This is very interesting for modelling approaches which use the functional groups of species to represent marine food webs (Plaganyi 2007) because they require sound criteria in order to define groups as realistically as possible. In addition, the analysis of environmental variables and fishing pressure showed different gradients structuring the demersal assemblage, with different levels of influence distributed at different spatial scales. 
The response of the demersal community to climate change and anthropogenic disturbances is not easy to detect because of the increase in sensitivity of marine populations to climate variability due to fishing impacts (Perry et al. 2010), and the dynamics of functional groups in the demersal assemblage may be affected by mitigation processes, such as compensation among species, confusing the effects of fishing impact on assemblages (Rochet et al. 2013). Thus, additional studies in terms of changes in functional group composition in the long term are required for a better understanding of the observed fluctuations.

Acknowledgements. This work was carried out within the Action SP2-WP2-AZ3 of the Flagship Project RITMARE The Italian Research for the Sea - coordinated by the Italian National Research Council and funded by the Italian Ministry of Education, University and Research within the National Research Program 2011-2013. We thank the anonymous reviewers for their contributions to revisions, useful suggestions and advice.

\section{LITERATURE CITED}

Bandelj V, Socal G, Park YS, Lek S and others (2008) Analysis of multitrophic plankton assemblages in the Lagoon of Venice. Mar Ecol Prog Ser 368:23-40

Bertrand JA, Gil de Sola L, Papaconstantinou C, Relini G, Souplet A (2000) An international bottom trawl survey in the Mediterranean: the MEDITS programme. IFREMER Actes Colloq 26:76-93

Bianchi CN, Morri C, Chiantore M, Montefalcone M, Parravicini V, Rovere A (2012) Mediterranean Sea biodiversity between the legacy from the past and a future of change. In: Stambler N (ed) Life in the Mediterranean Sea: a look at habitat changes. Nova Science Publishers, New York, NY, p 1-55

Butler M, Bollens S, Burkhalter B, Madin L, Horgan E (2001) Mesopelagic fishes of the Arabian Sea: distribution, abundance and diet of Chauliodus pammelas, Chauliodus sloani, Stomias affinis, and Stomias nebulosus. Deep Sea Res II 48:1369-1383

Capezzuto F, Carlucci R, Maiorano P, Sion L and others (2010) The bathyal benthopelagic fauna in the northwestern Ionian Sea: structure, patterns and interactions. Chem Ecol 26:199-217

Carlucci R, Lembo G, Maiorano P, Capezzuto F and others (2009a) Nursery areas of red mullet (Mullus barbatus), hake (Merluccius merluccius) and deep-water rose shrimp (Parapenaeus longirostris) in Eastern-Central Mediterranean Sea. Estuar Coast Shelf Sci 83:529-538

Carlucci R, Capezzuto F, Maiorano P, Sion L, D'Onghia G (2009b) Distribution, population structure and dynamics of the black anglerfish (Lophius budegassa) (Spinola, 1987) in the Eastern Mediterranean Sea. Fish Res 95: 76-87

Carlucci R, Maiorano P, Sion L, D'Onghia G, Tursi A (2016) The sustainability of fishing in the southern Adriatic and Northern Ionian Seas. In: Caligiuri A (ed) Gover- nance of the Adriatic and Ionian marine space. Editoriale Scientifica, Naples, p 149-159

Carpentieri P, Colloca F, Cardinale M, Belluscio A, Ardizzone GD (2005) Feeding habits of European hake (Merluccius merluccius) in the central Mediterranean Sea. Fish Bull 103:411-416

* Carrassón M, Stefanescu C, Cartes JE (1992) Diets and bathymetric distributions of two bathyal sharks of the Catalan deep sea (western Mediterranean). Mar Ecol Prog Ser 82:21-30

Cartes JE (1993) Diets of deep-water pandalid shrimps on the Western Mediterranean slope. Mar Ecol Prog Ser 96: 49-61

Civitarese G, Gacìc M, Lipizer M, Eusebi Borzelli GL (2010) On the impact of the Bimodal Oscillating System (BiOS) on the biogeochemistry and biology of the Adriatic and Ionian Seas (Eastern Mediterranean). Biogeosciences 7: 3987-3997

Coll M, Libralato S (2012) Contributions of food-web modelling for an ecosystem approach of marine resource management in the Mediterranean Sea. Fish Fish 13:60-88

Coll M, Piroddi C, Albouy C, Lasram FBR and others (2012) The Mediterranean Sea under siege: spatial overlap between marine biodiversity, cumulative threats and marine reserves. Glob Ecol Biogeogr 21:465-480

Colloca F, Cardinale M, Belluscio A, Ardizzone GD (2003) Pattern of distribution and diversity of demersal assemblages in the central Mediterranean sea. Estuar Coast Shelf Sci 56:469-480

Colloca F, Carpentieri P, Balestri E, Ardizzone GD (2004) A critical habitat for Mediterranean fish resources: shelfbreak areas with Leptometra phalangium (Echinodermata: Crinoidea). Mar Biol 145:1129-1142

Colloca F, Carpentieri P, Balestri E, Ardizzone GD (2010) Food resource partitioning in a Mediterranean demersal fish assemblage: the effect of body size and niche width. Mar Biol 157:565-574

* D'Onghia G, Tursi A, Maiorano P, Matarrese A, Panza M (1998) Demersal fish assemblages from the bathyal grounds of the Ionian Sea (middle eastern Mediterranean). Ital J Zool 65:287-292

* D'Onghia G, Mastrototaro F, Matarrese A, Politou CY, Mytilineou C (2003) Biodiversity of the upper slope demersal community in the eastern Mediterranean: preliminary comparison between two areas with and without trawl fishing. J Northwest Atl Fish Sci 31:263-273

* D'Onghia G, Politou CY, Bozzano A, Lloris D, Rotllant G, Sion L, Mastrototaro F (2004) Deep-water fish assemblages in the Mediterranean Sea. Sci Mar 68:87-99

* D'Onghia G, Indennidate A, Giove A, Savini A and others (2011) Distribution and behaviour of the deep-sea benthopelagic fauna observed using towed cameras in the Santa Maria di Leuca cold-water coral province. Mar Ecol Prog Ser 443:95-110

D'Onghia G, Giove A, Maiorano P, Carlucci R and others (2012a) Exploring relationships between demersal resources and environmental factors in the Ionian Sea (Central Mediterranean). J Mar Biol 2012:279406

* D'Onghia G, Maiorano P, Carlucci R, Capezzuto F, Carluccio A, Tursi A, Sion L (2012b) Comparing deep-sea fish fauna between coral and non-coral 'megahabitats' in the Santa Maria di Leuca cold-water coral province (Mediterranean Sea). PLOS ONE 7:e44509

* D'Onghia G, Calculli C, Capezzuto F, Carlucci R and others (2016) New records of cold-water coral sites and fish 
fauna characterization of a potential network existing in the Mediterranean Sea. Mar Ecol 37:1398-1422

'D'Ortenzio F, Ragni M, Marullo S, Ribera d'Alcalà M (2003) Did biological activity in the Ionian Sea change after the Eastern Mediterranean Transient? Results from the analysis of remote sensing observations. J Geophys Res C Oceans 108:9-20

De Cáceres M, Legendre P (2009) Associations between species and groups of sites: indices and statistical inference. Ecology 90:3566-3574

Dufrêne M, Legendre P (1997) Species assemblages and indicator species: the need for a flexible asymmetrical approach. Ecol Monogr 67:345-366

EC (European Commission) (2006) Council Regulation (EC) No 1967/2006 of 21 December 2006 concerning management measures for the sustainable exploitation of fishery resources in the Mediterranean Sea, amending Regulation (EEC) No 2847/93 and repealing Regulation (EC) No 1626/94. Off J Eur Union L 409:11-85

EC (2008) Directive 2008/56/EC of the European Parliament and of the Council of 17 June 2008 establishing a framework for community action in the field of marine environment policy (Marine Strategy Framework Directive). Off J Eur Union 164:19-40

Fernandez-Arcaya U, Ramirez-Llodra E, Aguzzi J, Allcock AL and others (2017) Ecological role of submarine canyons and need for canyon conservation: a review. Front Mar Sci 4:5

Gaertner JC, Maiorano P, Mérigot B, Colloca F and others (2013) Large-scale diversity of slope fishes: pattern inconsistency between multiple diversity indices. PLOS ONE 8:e66753

García-Rodríguez M, Abellò $\mathrm{P}$, Fernàndez $\mathrm{A}$, Esteban $\mathrm{A}$ (2011) Demersal assemblages on the soft bottoms off the Catalan-Levante coast of the Spanish Mediterranean. J Mar Biol 2011:976396

* Granger V, Fromentin JM, Bez N, Relini G and others (2015) Large-scale spatio-temporal monitoring highlights hotspots of demersal fish diversity in the Mediterranean Sea. Prog Oceanogr 130:65-74

Grüss A, Drexler MD, Ainsworth CH, Babcock EA, Tarnecki $\mathrm{JH}$, Love MS (2018) Producing distribution maps for a spatially-explicit ecosystem model using large monitoring and environmental databases and a combination of interpolation and extrapolation. Front Mar Sci 5:16

Kapiris K, Thessalou-Legaki M, Petrakis G, Conides A (2010) Ontogenetic shifts and temporal changes in the trophic patterns of the deep-sea red shrimp, Aristaeomorpha foliacea (Decapods: Aristeidae), in the Eastern Ionian Sea (Eastern Mediterranean). Mar Ecol 31: 341-354

Klein B, Roether W, Manca B, Bregant D, Beitzel V, Kovacevic V, Luchetta A (1999) The large deep transient in the eastern Mediterranean. Deep Sea Res I 46:371-414

Kohonen T (2001) Self-organizing maps, 3rd edn. SpringerVerlag, Heidelberg

Lazzari P, Mattia G, Solidoro C, Salon S and others (2014) The impacts of climate change and environmental management policies on the trophic regimes in the Mediterranean Sea: scenario analyses. J Mar Syst 135: 137-149

Legendre P, De Cáceres M (2013) Betadiversity as the variance of community data: dissimilarity coefficients and partitioning. Ecol Lett 16:951-963

Legendre P, Gallagher ED (2001) Ecologically meaningful transformations for ordination of species data. Oecologia 129:271-280

Legendre P, Legendre L (2012) Numerical ecology, 3rd edn. Elsevier Science BV, Amsterdam

Lloret J, Palomera I, Salat J, Sole I (2004) Impact of freshwater input and wind on landings of anchovy (Engraulis encrasicolus) and sardine (Sardina pilchardus) in shelf waters surrounding the Ebre (Ebro) River delta (northwestern Mediterranean). Fish Oceanogr 13:102-110

Madurell T, Cartes JE (2005) Temporal changes in feeding habits and daily rations of Hoplostethus mediterraneus in the bathyal Ionian Sea (eastern Mediterranean). Mar Biol 146:951-962

Madurell T, Cartes JE (2006) Trophic relationships and food consumption of slope dwelling macrourids from the bathyal Ionian Sea (eastern Mediterranean). Mar Biol 148:1325-1338

* Maiorano P, D'Onghia G, Capezzuto F, Sion L (2002) Lifehistory traits of Plesionika martia (Decapoda: Caridea) from the eastern-central Mediterranean Sea. Mar Biol 141:527-539

* Maiorano P, Sion L, Carlucci R, Capezzuto F and others (2010) The demersal faunal assemblage of the northwestern Ionian Sea (central Mediterranean): current knowledge and perspectives. Chem Ecol 26:219-240

*Massutí E, Renones O (2005) Demersal resource assemblages in the trawl fishing grounds off the Balearic Islands (western Mediterranean). Sci Mar 69:167-181

Mazzocchi MG, Siokou I, Tirelli V, Bandelj V and others (2014) Regional and seasonal characteristics of epipelagic mesozooplankton in the Mediterranean Sea based on an artificial neural network analysis. J Mar Syst 135:64-80

Park YS, Céréghino R, Compin A, Lek S (2003) Applications of artificial neural networks for patterning and predicting aquatic insect species richness in running waters. Ecol Model 160:265-280

Peres JM, Picard J (1964) Nouveau manuel de bionomie benthique de la mer Mediteranee. Rec Trav St Mat Endoume 31:1-137

Perry RI, Cury P, Brander K, Jennings S, Möllmann C, Planque B (2010) Sensitivity of marine systems to climate and fishing: concepts, issues and management responses. Contributions from Advances in Marine Ecosystem Modelling Research II, 23-26 June 2008, Plymouth, UK 79:427-435

Plaganyi E (2007) Models for an ecosystem approach to fisheries. Fish Tech Pap 477. Food and Agriculture Organization, Rome

*Puig P, Palanques A, Guillen J, García-Ladona E (2000) Deep slope currents and suspended particle fluxes in and around the Foix submarine canyon (NW Mediterranean). Deep Sea Res I 47:343-366

Q Quetglas A, Ordines F, Hidalgo M, Monserrat S and others (2013) Synchronous combined effects of fishing and climate within a demersal community. ICES J Mar Sci 70: 319-328

Kamirez-Llodra E, Company JB, Sardà F, Rotllant G (2010) Megabenthic diversity patterns and community structure of the Blanes submarine canyon and adjacent slope in the North-western Mediterranean: a human overprint? Mar Ecol 31:167-182

Ramirez-Llodra E, Tyler PA, Baker MC, Bergstad OA and others (2011) Man and the last great wilderness: human impact on the deep sea. PLOS ONE 6:e22588 
Relini M, Maiorano P, D'Onghia G, Orsi Relini L, Tursi A, Panza M (2000) A pilot experiment of tagging the deep shrimp Aristeus antennatus (Risso, 1816). Sci Mar 64:357-361

Rochet MJ, Collie JS, Trenkel VM (2013) How do fishing and environmental effects propagate among and within functional groups? Bull Mar Sci 89:285-315

Rossi S, Gabbianelli G (1978) Geomorfologia del Golfo di Taranto. Boll Soc Geol Ital 97:423-437

Russo T, Scardi M, Cataudella S (2014) Applications of selforganizing maps for ecomorphological investigations through early ontogeny of fish. PLOS ONE 9:e86646

Russo T, Bitetto E, Carbonara P, Carlucci R and others (2017) A holistic approach to fishery management: evidence and insights from a Central Mediterranean case study (Western Ionian Sea). Front Mar Sci 4:193

Shephard S, Greenstreet SPR, Piet GJ, Rindorf A, DickeyCollas M (2015) Surveillance indicators and their use in implementation of the Marine Strategy Framework Directive. ICES J Mar Sci 72:2269-2277

Editorial responsibility: Alistair Hobday,

Hobart, Tasmania, Australia
Solidoro C, Bandelj V, Barbieri P, Cossarini G, Fonda Umani S (2007) Understanding dynamic of biogeochemical properties in the northern Adriatic Sea by using selforganizing maps and k-means clustering. J Geophys Res 112:C07S90

Stergiou KI, Karpouzi VS (2002) Feeding habits and trophic levels of Mediterranean fish. Rev Fish Biol Fish 11: $217-254$

Tam JC, Link JS, Rossberg AG, Rogers SI and others (2017) Towards ecosystem-based management: identifying operational food-web indicators for marine ecosystems. ICES J Mar Sci 74:2040-2052

* Vassallo P, D'Onghia G, Fabiano M, Maiorano P and others (2017) A trophic model of the benthopelagic fauna distributed in the Santa Maria di Leuca cold-water coral province (Mediterranean Sea). Energy Ecol Environ 2: 114-124

Whittaker RH (1972) Evolution and measurement of species diversity. Taxon 21:213-251

Submitted: July 28, 2017; Accepted: May 2, 2018

Proofs received from author(s): June 11, 2018 